\title{
PERBEDAAN TEKANAN DARAH PADA PASIEN HIPERTENSI ANTARA PASIEN DENGAN INDEKS MASSA TUBUH NORMAL DENGAN OVERWEIGHT DAN OBESITAS DI POLI KLINIK PENYAKIT DALAM BLUD RUMAH SAKIT UMUM CUT NYAK DHIEN MEULABOH
}

\author{
Bustami \\ Dosen Prodi Keperawatan Meulaboh Poltekkes Kemenkes Aceh \\ amitihar@yahoo.co.id
}

\begin{abstract}
ABSTRAK
Salah satu penyakit degeneratif yang perlu diwaspadai adalah penyakit hipertensi yaitu suatu gangguan dari sistem peredaran darah yang akhir-akhir ini cenderung mengenai segala usia. Penyakit ini sering disebut dengan penyakit darah tinggi karena memang terdapat adanya peningkatan tekanan darah yang melebihi batas normal. Kasus hipertensi di Provinsi Aceh tergolong tinggi. Berdasarkan hasil Riskesdas Tahun 2013 dilaporkan bahwa jumlah prevalensi hipertensi di Provinsi Aceh mencapai 9,5\% dan merupakan peringkat kedua tertinggi di Indonesia. Dinas Kesehatan Kabupaten Aceh Barat juga mencatat jumlah penderita hipertensi di Kabupaten Aceh Barat yang tidak sedikit, yaitu7,8\%. Dengan perbedaan berat badan pada penderita hipertensi ini besar kemungkinan juga akan berbeda ukuran tekanan darah secara rata-rata. Sehingga bila sudah terbukti ada perbedaan secara rata-rata maka intervensi yang diberikan dapat ditentukan lebih awal, dan juga perawat secara dini dapat mengantisipasi dampak lebih lanjut dari kejadian hipertensi pada pasien yang overweight. Jenis penelitian merupakan penelitian comparative Study. Metode sampel yang di gunakan yaitu Acidental sampling, dengan jumlah sampel sebanyak 30 orang responden. Metode analisa data adalah univariat dan bivariat. Hasil penelitian menunjukkan bahwa tekanan darah penderita hipertensi memiliki perbedaan yang signifikan baik antara yang normal dengan overweight, antara normal dengan obesitas, maupun antara overweight dengan obesitas. Berdasarkan uji $t$ (T-test) yang telah dilakukan seluruhnya menunjukkan nilai signifikansinya $<0,05 \quad(p<0,05)$, hal ini menunjukkan Ha diterima, artinya ada perbedaan yang signifikan rata-rata tekanan darah systole antara pasien yang memili IMT normal dengan overweight dan obesitas. Disarankan kepada pihak manajemen keperawatan RSUD Cut Nyak Dhien Meulaboh untuk mengambil kebijakan tentang penyuluhan dalam mengontrol berat badan penderita hipertensi.
\end{abstract}

Kata Kunci : Hipertensi, Indeks Massa Tubuh, Overweight, Obesitas

\section{PENDAHULUAN}

Hypertension Current Perspective (HCP) tahun 2008 menyatakan bahwa salah satu faktor risiko terjadinya hipertensi adalah obesitas. Cara untuk mengukur obesitas atau tidaknya seseorang secara langsung sangat sulit, untuk itu sebagai pengganti digunakan
Body Mass Index (BMI) atau Indeks Massa Tubuh (IMT) yaitu perbandingan berat badan (kilogram) dengan kuadrat tinggi badan (meter) (Sugondo, 2009).

Adanya peningkatan Free Fatty Acid (FFA), insulin, aldosteron, dan aktivitas rennin angiotensin yang disebabkan oleh obesitas akan menstimulasi peningkatan sistem saraf 
simpatis. Aktivitas peningkatan sistem saraf simpatis jangka panjang mampu menyebabkan peningkatan tekanan darah dengan cara vasokontriksi perifer dan peningkatan reabsorbsi natrium di tubulus ginjal (Lillyasari, 2007).

Saat ini diperkirakan jumlah orang di seluruh dunia dengan IMT $>30$ melebihi 250 juta orang, yaitu sekitar 7\% dari populasi orang dewasa di dunia (Sugondo, 2009). Di Amerika Serikat, $55 \%$ populasi mengalami kelebihan berat badan dan 22\% diantaranya obesitas (Ganong, 2002).

Indonesia saat ini penyakit kardiovaskular masih merupakan penyebab kematian utama. Menurut survei kesehatan rumah tangga, prevalensi penyakit jantung dan pembuluh darah menduduki urutan ke-3 pada tahun 1980 dengan prevalensi sebesar $9,9 \%$, meningkat menjadi $9,7 \%$ di urutan ke-2 pada tahun 1986, dan menduduki peringkat 1 pada tahun 1990 dengan prevalensi sebesar 16,5\% (Sugondo, 2009)

Sedangkan untuk populasi di Indonesia, angka kejadian hipertensi itu berdasarkan Riset Kesehatan Dasar (Riskedas) Departemen Kesehatan tahun 2013 Prevalensi hipertensi di Indonesia yang didapat melalui pengukuran pada umur $\geq 18$ tahun sebesar 25,8 persen, tertinggi di Bangka Belitung (30,9\%), diikuti Kalimantan Selatan (30,8\%), Kalimantan Timur $(29,6 \%)$ dan Jawa Barat $(29,4 \%)$. Prevalensi hipertensi di Indonesia yang didapat melalui kuesioner terdiagnosis tenaga kesehatan sebesar 9,4 persen, yang didiagnosis tenaga kesehatan atau sedang minum obat sebesar 9,5 persen. Jadi, ada 0,1 persen yang minum obat sendiri. Responden yang mempunyai tekanan darah normal tetapi sedang minum obat hipertensi sebesar 0.7 persen. Jadi prevalensi hipertensi di Indonesia sebesar 26,5 persen $(25,8 \%+0,7 \%)$ (Kemenkes, 2013).

Kasus hipertensi di Provinsi Aceh tergolong tinggi. Berdasarkan hasil Riskesdas Tahun 2013 dilaporkan bahwa jumlah prevalensi hipertensi di Provinsi Aceh mencapai 9,5\% dan merupakan peringkat kedua tertinggi di Indonesia. Dinas Kesehatan Kabupaten Aceh Barat juga mencatat jumlah penderita hipertensi di Kabupaten Aceh Barat yang tidak sedikit, yaitu $7,8 \%$ orang.

Hasil survei yang penulis lakukan di poliklinik penyakit dalam BLUD RSUD Cut Nyak Dhien Meulaboh bahwa pada pasien yang mengalami overweight dan Obesitas ada kecenderungan memiliki nilai tekanan darah lebih tinggi bila dibandingkan dengan pasien dengan IMT normal.

Petugas kesehatan di Poliklinik Penyakit Dalam menyatakan bahwa kebanyakan penderita hipertensi yang berobat memiliki berat badan lebih atau overweight. Kondisi berat badan yang berlebih atau overweight memang beresiko terkena hipertensi. Namun bukan berarti orang yang tidak overweight tidak bisa terkena hipertensi mengingat bahwa hipertensi bukan disebabkan oleh faktor tunggal.

Dengan perbedaan berat badan pada penderita hipertensi ini besar kemungkinan juga akan berbeda ukuran tekanan darah secara rata-rata. Sehingga bila sudah terbukti ada perbedaan secara rata-rata maka intervensi yang diberikan dapat ditentukan lebih awal, dan juga perawat secara dini dapat mengantisipasi dampak lebih lanjut dari kejadian hipertensi pada pasien yang overweight.

\section{METODE PENELITIAN}

Jenis penelitian ini adalah eksperimen semu dengan rancangan comparatif study, yang dilakukan dengan cara membandingkan persamaan dan 
perbedaan sebuah fenomena untuk mencari factor yang menyebabkan suatu gejala.

Penelitian ini dilaksanakan di BLUD Rumah Sakit Umum Daerah Cut Nyak Dhien Meulaboh pada bulan Agustus-September 2017.

Sampel dikelompokkan menjadi 3 kelompok sampel yaitu pasien hipertensi dengan IMT normal, pasien hipertensi dengan IMT overweight dan Obesitas. Peneliti memutuskan untuk menentukan jumlah sampel sebanyak 30 orang, yaitu 10 pasien dengan IMT normal untuk kelompok pertama, 10 pasien dengan IMT overweight untuk kelompok kedua, dan 10 pasien dengan IMT Obesitas untuk kelompok ketiga. Pengambilan sampel menggunakan metode accidental sampling

Data dikumpulkan dengan menggunakan alat ukur tekanan darah yaitu spigmomanometer, meteran badan dan timbangan berat badan. Pelaksanaan pengumpulan data dengan cara memeriksa tekanan darah dan IMT dengan mengukur tinggi badan dan berat badan.

Analisis data dilakukan menggunakan uji statistik (Uji t-test) karena uji ini termasuk uji statistik parametrik untuk uji beda 2 mean tidak berhubungan.

\section{HASIL DAN PEMBAHASAN \\ Karakteristik Responden}

Karakteristik responden disajikan dalam tabel distribusi frekuensi yang terdiri dari umur, pendidikan, dan pekerjaan. Secara lengkap karakteristik responden dapat dilihat pada tabel berikut:

Tabel 1. Distribusi Frekuensi Responden Berdasarkan Karakteristik di BLUD RSUD Cut Nyak Dhien Meulaboh 2017

\begin{tabular}{llcc}
\hline No & Kategori & Jumlah & $(\%)$ \\
\hline & Umur & & \\
1 & Dewasa & 7 & 23,33 \\
\hline
\end{tabular}

\begin{tabular}{llcc}
\hline 2 & Menengah & 12 & 40,00 \\
3 & $\begin{array}{l}\text { Dewasa Tua } \\
\text { Lansia }\end{array}$ & 11 & 36,67 \\
\hline & Total & 30 & 100 \\
\hline & Jenis Kelamin & & \\
1 & Laki-laki & 18 & 60 \\
2 & Perempuan & 12 & 40 \\
\hline & & 30 & 100 \\
\hline & Pekerjaan & & \\
1 & PNS & 5 & 16,67 \\
2 & Swasta & 6 & 20,00 \\
3 & Pensiunan & 5 & 16,67 \\
4 & Tani & 4 & 13,33 \\
5 & IRT & 10 & 33,33 \\
\hline & Total & 30 & 100 \\
\hline Sum & Dot Data Primer tahin
\end{tabular}

Sumber : Data Primer tahun 2017

Dari tabel di atas dapat diketahui bahwa mayoritas responden berumur dewasa tua yaitu 12 orang $(40 \%)$, Jenis kelamin terbanyak adalah laki-laki yaitu 18 orang $(60 \%)$ dan sebagian besar bekerja sebagai ibu rumah tangga yaitu 10 orang (33,3\%).

\section{Indeks Masa Tubuh (IMT)}

Indeks masa tubuh penderita hipertensi di kelompokkan menjadi 3 kategori yaitu normal, overweight, dan obesitas. Hasil pengukuran IMT dapat dilihat pada tabel berikut ini :

Tabel. 2 Distribusi Frekuensi Responden Berdasarkan Indeks Masa Tubuh (IMT) di BLUD RSUD Cut Nyak Dhien Meulaboh 2017

\begin{tabular}{llcc}
\hline No & Kategori & Frekuensi & $\%$ \\
\hline 1 & Normal & 10 & 33,33 \\
2 & Overweight & 10 & 33,33 \\
3 & Obesitas & 10 & 33,33 \\
\hline & Jumlah & 30 & 100 \\
\hline
\end{tabular}

Sumber : Data Primer tahun 2017

Berdasarkan tabel di atas dapat diketahui bahwa jumlah responden untuk setiap kelompok adalah sama yaitu 10 orang.

\section{Tekanan Darah}

Tekanan darah penderita hipertensi dalam penelitian ini dikategorikan menjadi 2 yaitu, hipertensi stadium I, dan hipertensi 
stadium II. Hasil pengukuran skala nyeri dapat dilihat pada tabel berikut ini :

Tabel 3. Distribusi Frekuensi Responden Berdasarkan tekanan darah di BLUD RSUD Cut Nyak Dhien Meulaboh 2017

\begin{tabular}{llcc}
\hline No & Kategori & Frekuensi & $\%$ \\
\hline 1 & Hipertensi Stadium I & 14 & 46,67 \\
2 & Hipertensi Stadium & 16 & 53,33 \\
& II & & \\
\hline & Jumlah & 30 & 100 \\
\hline
\end{tabular}

Sumber : Data Primer tahun 2017

Berdasarkan tabel di atas dapat diketahui bahwa hipertensi yang dialami responden kebanyakan berada pada stadium II yaitu 16 orang $(53,33 \%)$.

\section{Perbedaan Tekanan Darah Sistole Antara Pasien dengan IMT Normal dan Overweight}

Pengukuran perbedaan tekanan darah sistole antara pasien dengan IMT normal dan Overweight dilakukan menggunakan Uji t (T-Test)

Tabel 4. Hasil Uji Perbedaan Tekanan Darah Sistole Antara Pasien dengan IMT Normal dan Overweight

\begin{tabular}{|c|c|c|c|c|c|c|c|}
\hline & & $\mathrm{F}$ & Sig. & $\mathrm{t}$ & $\mathrm{df}$ & $\begin{array}{l}\text { Sig. (2- } \\
\text { tailed) }\end{array}$ & $\begin{array}{c}\text { Mean } \\
\text { Differ } \\
\text { ence }\end{array}$ \\
\hline \multirow{2}{*}{$\begin{array}{l}\text { Teka } \\
\text { nan } \\
\text { darah } \\
\text { sistol }\end{array}$} & $\begin{array}{l}\text { Equal } \\
\text { variances } \\
\text { assumed }\end{array}$ & .025 & .876 & 3.236 & 18 & .005 & 8.000 \\
\hline & $\begin{array}{l}\text { Equal } \\
\text { variances } \\
\text { not } \\
\text { assumed }\end{array}$ & & & 3.236 & $\begin{array}{c}17.94 \\
7\end{array}$ & .005 & 8.000 \\
\hline
\end{tabular}

Dari tabel diatas diketahui bahwa hasil uji Farian dapat dilihat dari nilai Sig. 0,876 ( $p>0,05)$, sehingga Ha ditolak yang berarti varian dari data di atas tidak berbeda. Selanjutnya hasil uji t (T-Test) dapat dilihat pada baris equal variances assumed dimana nilai $t_{\text {hitung }}=3,236$ $\left(\mathrm{t}_{\text {tabel }}=1,743\right)$ dan signifikansinya adalah $0,005(<0,05)$, hal ini menunjukkan $\mathrm{Ha}$ diterima, artinya ada perbedaan yang signifikan tekanan darah sistol antara pasien overweight dengan pasien normal.

\section{Perbedaan Tekanan Darah Sistole Antara Pasien dengan IMT Normal dan Obesitas}

Pengukuran perbedaan tekanan darah sístole antara pasien dengan IMT normal dan Obesitas dilakukan menggunakan Uji $t$ (T-Test). Hasil analisis bivariat dapat dilihat pada tabel berikut :

Tabel 5. Hasil Uji Perbedaan Tekanan Darah Sistole Antara Pasien dengan IMT Normal dan Obesitas

\begin{tabular}{lcc|ccccc}
\hline & & & & \multicolumn{3}{c}{$\begin{array}{c}\text { Mean } \\
\text { Sig. (2- Differe } \\
\text { tailed) }\end{array}$} & nce \\
\hline $\begin{array}{l}\text { Teka Equal } \\
\text { nan variances }\end{array}$ & .155 & .698 & 6.871 & 18 & .000 & 18.500 \\
$\begin{array}{l}\text { darah assumed } \\
\text { sistol } \begin{array}{l}\text { Equal } \\
\text { variances } \\
\text { not } \\
\text { assumed }\end{array}\end{array}$ & & & & & & & \\
\hline
\end{tabular}

Dari tabel diatas dapat diketahui bahwa hasil uji Farian dapat dilihat dari nilai Sig. $0,698$ ( $p>0,05)$, sehingga Ha ditolak yang berarti varian dari data di atas tidak berbeda. Selanjutnya hasil uji t (T-Test) dapat dilihat pada baris equal variances assumed dimana nilai thitung 6,871 $\left(\mathrm{t}_{\text {tabel }}=1,743\right)$ dan signifikansinya adalah $0,000(<0,05)$, hal ini menunjukkan $\mathrm{Ha}$ diterima, artinya ada perbedaan yang signifikan tekanan darah sistol antara pasien obesitas dengan pasien normal.

\section{Perbedaan Tekanan Darah Sistole Antara Pasien dengan IMT Overweight dan Obesitas}

Pengukuran perbedaan tekanan darah sístole antara pasien dengan IMT Overweight dan Obesitas dilakukan menggunakan $\mathrm{Uji} \mathrm{t}$ (T-Test). Hasil analisis bivariat dapat dilihat pada tabel berikut : 
Tabel 6. Hasil Uji Perbedaan Tekanan Darah Sistole Antara Pasien dengan IMT Overweight dan Obesitas

\begin{tabular}{|c|c|c|c|c|c|c|}
\hline & F & Sig. & $\mathrm{t}$ & df & $\begin{array}{l}\text { Sig. (2- } \\
\text { tailed) }\end{array}$ & $\begin{array}{l}\text { Mean } \\
\text { Differe } \\
\text { nce }\end{array}$ \\
\hline $\begin{array}{l}\text { Teka Equal } \\
\text { nan variances } \\
\text { darah assumed }\end{array}$ & .089 & .768 & 3.992 & 18 & .001 & 10.500 \\
\hline $\begin{array}{l}\text { sistol Equal } \\
\text { variances } \\
\text { not } \\
\text { assumed }\end{array}$ & & & 3.992 & 17.525 & .001 & 10.500 \\
\hline
\end{tabular}

Dari tabel diatas menunjukkan bahwa hasil uji Farian dapat dilihat dari nilai Sig. $0,768$ ( $p>0,05)$, sehingga Ha ditolak yang berarti varian dari data di atas tidak berbeda. Selanjutnya hasil uji t (T-Test) dapat dilihat pada baris equal variances assumed dimana nilai thitung 3,992 $\left(\mathrm{t}_{\text {tabel }}=1,743\right)$ dan signifikansinya adalah $0,001(<0,05)$, hal ini menunjukkan $\mathrm{Ha}$ diterima, artinya ada perbedaan yang signifikan tekanan darah sistol antara pasien obesitas dengan pasien overweight

\section{Perbedaan Tekanan Darah Diastole Antara Pasien dengan IMT Normal dan Overweight}

Tabel 7. Hasil Uji Perbedaan Tekanan Darah Diastole Antara Pasien dengan IMT Normal dan Overweight

\begin{tabular}{|c|c|c|c|c|c|c|c|}
\hline & & $\mathrm{F}$ & Sig. & $\mathrm{t}$ & Df & $\begin{array}{l}\text { Sig. } \\
(2- \\
\text { taile } \\
\text { d) }\end{array}$ & $\begin{array}{c}\text { Mean } \\
\text { Differ } \\
\text { ence }\end{array}$ \\
\hline \multirow[t]{2}{*}{$\begin{array}{l}\text { Tekanan } \\
\text { darah } \\
\text { diastol }\end{array}$} & $\begin{array}{l}\text { Equal } \\
\text { variances } \\
\text { assumed }\end{array}$ & .543 & .471 & 2.605 & 18 & .018 & -7.000 \\
\hline & $\begin{array}{l}\text { Equal } \\
\text { variances } \\
\text { not } \\
\text { assumed }\end{array}$ & & & 2.605 & 16.848 & .019 & -7.000 \\
\hline
\end{tabular}

Dari tabel diatas dapat diketahui bahwa hasil uji Farian dapat dilihat dari nilai Sig. 0,471 ( $>00,05)$, sehingga Ha ditolak yang berarti varian dari data di atas tidak berbeda. Selanjutnya hasil uji $t$ (T-Test) dapat dilihat pada baris equal variances assumed dimana nilai thitung 2,605 ( $\left.\mathrm{t}_{\text {tabel }}=1,743\right)$ dan signifikansinya adalah $0,018 \quad(<0,05)$, hal ini menunjukkan $\mathrm{Ha}$ diterima, artinya ada perbedaan yang signifikan tekanan darah diastol antara pasien normal dengan pasien overweight

\section{Perbedaan Tekanan Darah Diastole Antara Pasien dengan IMT Normal dan Obesitas}

Tabel 8. Hasil Uji Perbedaan Tekanan Darah Diastole Antara Pasien dengan IMT Normal dan Obesitas

\begin{tabular}{|c|c|c|c|c|c|c|c|}
\hline & & $\mathrm{F}$ & Sig. & $\mathrm{t}$ & df & $\begin{array}{l}\text { Sig. } \\
(2- \\
\text { tailed) }\end{array}$ & $\begin{array}{c}\text { Mean } \\
\text { Differ } \\
\text { ence }\end{array}$ \\
\hline \multirow[t]{2}{*}{$\begin{array}{l}\text { Tekanan } \\
\text { darah } \\
\text { diastol }\end{array}$} & $\begin{array}{l}\text { Equal } \\
\text { variances } \\
\text { assumed }\end{array}$ & .261 & .616 & $\begin{array}{c}3.95 \\
2\end{array}$ & 18 & .001 & 12.000 \\
\hline & $\begin{array}{l}\text { Equal } \\
\text { variances } \\
\text { not } \\
\text { assumed }\end{array}$ & & & $\begin{array}{c}3.95 \\
2\end{array}$ & $\begin{array}{c}17.4 \\
31\end{array}$ & .001 & 12.000 \\
\hline
\end{tabular}

Dari tabel diatas dapat terlihat bahwa hasil uji Farian dapat dilihat dari nilai Sig. 0,616 ( $>>0,05)$, sehingga Ha ditolak yang berarti varian dari data di atas tidak berbeda. Selanjutnya hasil uji t (T-Test) dapat dilihat pada baris equal variances assumed dimana nilai thitung $3,952 \quad\left(\mathrm{t}_{\text {tabel }}=1,743\right) \quad$ dan signifikansinya adalah $0,001(<0,05)$, hal ini menunjukkan $\mathrm{Ha}$ diterima, artinya ada perbedaan yang signifikan tekanan darah diastol antara pasien normal dengan pasien obesitas

\section{Perbedaan Tekanan Darah Diastole Antara Pasien dengan IMT Overweight dan Obesitas}

Tabel 9. Hasil Uji Perbedaan Tekanan Darah Diastole Antara Pasien dengan IMT Overweight dan Obesitas 


\begin{tabular}{|c|c|c|c|c|c|c|c|}
\hline & & $\mathrm{F}$ & Sig. & $\mathrm{t}$ & $\mathrm{df}$ & $\begin{array}{l}\text { Sig. } \\
(2- \\
\text { taile } \\
\text { d) }\end{array}$ & $\begin{array}{l}\text { Mean } \\
\text { Differ } \\
\text { ence }\end{array}$ \\
\hline \multirow{2}{*}{$\begin{array}{l}\text { Tekan } \\
\text { an } \\
\text { darah } \\
\text { diastol }\end{array}$} & $\begin{array}{l}\text { Equal } \\
\text { variances } \\
\text { assumed }\end{array}$ & .534 & .474 & 2.771 & 18 & .013 & 8.000 \\
\hline & $\begin{array}{l}\text { Equal } \\
\text { variances } \\
\text { not } \\
\text { assumed }\end{array}$ & & & 2.771 & $\begin{array}{c}17.8 \\
45\end{array}$ & .013 & 8.000 \\
\hline
\end{tabular}

Dari tabel diatas menunjukkan bahwa hasil uji Farian dapat dilihat dari nilai Sig. 0,474 ( $>00,05)$, sehingga $\mathrm{Ha}$ ditolak yang berarti varian dari data di atas tidak berbeda. Selanjutnya hasil uji t (T-Test) dapat dilihat pada baris equal variances assumed dimana nilai $t_{\text {hitung }}$ 2,771 ( $\left.\mathrm{t}_{\text {tabel }}=1,743\right)$ signifikansinya adalah $0,013(<0,05)$, hal ini menunjukkan $\mathrm{Ha}$ diterima, artinya ada perbedaan yang signifikan tekanan darah diastol antara pasien overweight dengan pasien obesitas

Hasil penelitian menunjukkan bahwa tekanan darah penderita hipertensi memiliki perbedaan yang signifikan baik antara yang normal dengan overweight, antara normal dengan obesitas, maupun antara overweight dengan obesitas. Berdasarkan uji $\mathrm{t}$ (T-test) yang telah dilakukan seluruhnya menunjukkan nilai signifikansinya $<0,05 \quad(p<0,05)$, hal ini menunjukkan $\mathrm{Ha}$ diterima, artinya ada perbedaan yang signifikan rata-rata tekanan darah systole antara pasien yang memilih IMT normal dengan overweight dan obesitas.

Terdapatnya perbedaan ini menunjukkan bahwa kondisi nilai Indeks Masa Tubuh (IMT) orang yang menderita hipertensi akan mempengaruhi tekanan darah penderita hipertensi tersebut. Semakin tinggi IMT seseorang maka ada kecenderungan semakin tinggi pula tekanan darahnya.
Berat badan merupakan faktor determinan pada tekanan darah pada kebanyakan kelompok etnik di semua umur. Menurut National Institutes for Health USA (NIH,1998), prevalensi tekanan darah tinggi pada orang dengan Indeks Massa Tubuh (IMT) $>30$ (obesitas) adalah 38\% untuk pria dan 32\% untuk wanita, dibandingkan dengan prevalensi $18 \%$ untuk pria dan $17 \%$ untuk wanita bagi yang memiliki IMT $<25$ (status gizi normal menurut standar internasional) (Cortas, 2008).

Hal ini dikarenanakan bahwa dampak buruk dari kegemukan atau overweight adalah peningkatan kolesterol LDL dan penurunan kolesterol HDL karena asupan makanan yang tidak sehat dan tinggi lemak. Fungsi dari kolesterol LDL adalah membawa kolesterol dari hati ke jaringan perifer atau dinding arteri, sedangkan fungsi HDL adalah membawa kolesterol dari dinding arteri ke hepar untuk di metabolisme. Karena LDL bersifat aterogenik dibandingkan dengan HDL dan lipoprotein lain sehingga LDL mampu menempel pada endotel dan merusak endotel bahkan dapat menimbulkan aterosklerosis yang ditandai dengan lesi intima yang disebut dengan ateroma, atau plak ateromatosa yang menonjol ke dalam dan menyumbat lumen pembuluh darah, memperlemah media dibawahnya, dan mungkin mengalami penyulit yang serius.

Hasil penelitian ini sesuai dengan hasil penelitian Lathifahayyu (2014) bahwa dari hasil penelitian didapatkan terdapat perbedaan tekanan darah dengan indeks massa tubuh normal dan overweight pada pasien hipertensi baik tekanan darah sistol maupun diastol. $(\mathrm{p}<0,05)$.

Dari hasil penelitian ini, bagi penderita hipertensi direkomendasikan untuk mengontrol berat jangan sampai terjadi overweight apalagi obesitas yang akan 
memperburuk kondisi penyakit hipertensi yang dideritanya

\section{KESIMPULAN}

Dari analisis data terhadap hasil penelitian, dapat disimpulkan bahwa tekanan darah penderita hipertensi memiliki perbedaan yang signifikan baik antara yang normal dengan overweight, antara normal dengan obesitas, maupun antara overweight dengan obesitas baik sistol maupun diastol. Berdasarkan uji $t$ (T-test) yang telah dilakukan seluruhnya menunjukkan nilai signifikansinya $<0,05$ $(\mathrm{p}<0,05)$.

\section{SARAN}

Disarankan kepada pihak manajemen keperawatan RSUD Cut Nyak Dhien Meulaboh untuk mengambil kebijakan tentang penyuluhan dalam mengontrol berat badan penderita hipertensi.

\section{DAFTAR PUSTAKA}

Armilawaty, 2007. Hipertensi dan Faktor Risikonya dalam Kajian Epidemiologi. Bagian Epidemiologi FKM UNHAS.

Ganong, 2010. Buku Ajar Fisiologi Kedokteran .Jakarta. EGC.

Hidayat, 2006. Kebutuhan dasar manusia . Salemba medika. Jakarta

Kemenkes, 2013. Riset Kesehatan Dasar. Jakarta

Kumar, 2008. Hypertensive And Atherosclerotic Cardiovascular Disease, In: Heart Disease A Textbook Of Cardiovascular Medicine 6th Edition. Philadelphia: W.B.Saunders Company pp. 93

Lillyasari, 2007. Hipertensi Dengan Obesitas: Adakah Peran Endotelin-1 Jurnal Kardiologi Indonesia. 28: 460475.
Muttaqin, 2009. Penggunaan Berbagai Cut-Off Indeks Massa Tubuh Sebagai Indikator Obesitas Terkait Penyakit Degeneratif di Indonesia. Gizi

Notoatmodjo, 2010. Metodologi Penelitian Kesehatan, Rineka Cipta. Jakarta

Oktora, 2006. Penyakit yang Paling Mematikan. Buana Pustaka. Jakarta

Smeltzer, 2014. Keperawatan Medikal Bedah Brunner \& Suddarth. EGC. Jakarta

Sugondo, 2009. Hipertensi Esensial. Buku Ajar Ilmu Penyakit Dalam. EGC Jakarta

Suliswati, 2005. Konsep Dasar Keperawatan dan Kesehatan Jiwa. EGC. Jakarta

Suyanto, 2010. Metodologi Penelitian Balai Pustaka. Jakarta

Tilong, 2014 . Waspasda !!! Penyakitpenyakit Mematikan tanpa Gejala Menyolok. Buku biru. Jogjakarta

Widayanto, 2009. Impact of Body Mass Index on Sex Differences.

Yogiantoro, 2006. Hipertensi Esensial, In: Sudoyo, AW., Setiyohadi, B., Alwi, I.,Simadibrata, M., Setiati, S., editor. Buku Ajar Ilmu Penyakit Dalam Jilid I. Penerbit Departemen Ilmu Penyakit Dalam FK UI pp. 599. Jakarta 